\title{
An Experimental Study on Ballistics Performance: Functionally Graded Sandwich Plate Impacted by a $9 \mathrm{~mm}$ Parabellum Projectile
}

\author{
M. Aydin ${ }^{1}$, M. K. Apalak ${ }^{2}$, R. Gunes ${ }^{3}$, J. N. Reddy ${ }^{4}$ \\ ${ }^{1}$ Department of Aeronautical Engineering, Erciyes University, Kayseri 38039, Turkey, aydin@erciyes.edu.tr \\ ${ }^{2}$ Department of Mechanical Engineering, Erciyes University, Kayseri 38039, Turkey, apalakmk@erciyes.edu.tr \\ ${ }^{3}$ Department of Mechanical Engineering, Erciyes University, Kayseri 38039, Turkey, recepg@erciyes.edu.tr \\ ${ }^{4}$ Department of Mechanical Engineering, Texas AM University, College Station, TX 77843-3123, USA, jnreddy@tamu.edu.tr
}

\begin{abstract}
Functionally graded materials have been increasingly used in the design of impact resistant structures. A functionally graded plate with a tailored ceramic to metal through-thickness gradient combines the superior features of ceramics and metals in the same material system. The ceramic-rich side provides good protection against projectiles, while the metal-rich side offers toughness and strength to maintain the integrity of the structure as much as possible. Thus, the ceramic plates are used for single impact applications, whereas the FGM can be used multiple impact applications with high ballistic performance.

In this study, the damage and deformation mechanisms of aluminum plates and functionally graded sandwich plates have been investigated and their performances were compared to each other under ballistics impact loadings. The functionally graded sandwich plate is composed of a mixture of ceramic $(\mathrm{SiC})$ and metal $(\mathrm{Al})$ phases, at a ratio of which is determined by a power-law distribution of the volume fraction. In the ballistics tests with $9 \mathrm{~mm}$ Parabellum projectiles, having a brass jacket and a lead core were used. Both aluminum and functionally graded sandwich plates were manufactured by means of the powder stacking-hot pressing method, their ballistic tests were performed and it was determined that functionally graded sandwich plates have a better ballistics performance than an aluminum plate by examining almost a full penetration of projectile to the aluminum plate while a significant penetration to the functionally graded sandwich plate was not observed.
\end{abstract}

Keywords: Functionally graded materials (FGMs), Ballistic performance, Sandwich plates

\section{Introduction}

Development of high-performance and light armors has become a critical requirement against emerging threats. The research for new materials in this field has brought ceramic-faced composite armors to the forefront. Eventhough having high hardness, thermal resistance and compressive strength, ceramics are not used as armor alone due to their brittle. In a firearm shot, through ceramic material, while the ceramic front-surface deforms tip of the bullet piercing, back-surface of the metal or fiber-reinforced polymer matrix composite absorbs the energy and prevents the perforation. Layered composite structures are widely used in ballistic systems due to their high strength and high stiffness. An abrupt change in their material properties across an interface between discrete materials introduces large interlaminar stresses that could cause delamination $[1,2]$. One way to overcome this adverse effect is to use a functionally graded material (FGM).

The mechanical and physical properties of functionally graded material (FGM) vary continuously along a direction in the macroscopic sense. In general, they are composed of ceramic and metal, and are most suitable structures

Presenting and corresponding author: M. Kemal Apalak, Department of Mechanical Engineering, Erciyes University, Kayseri 38039, Turkey 


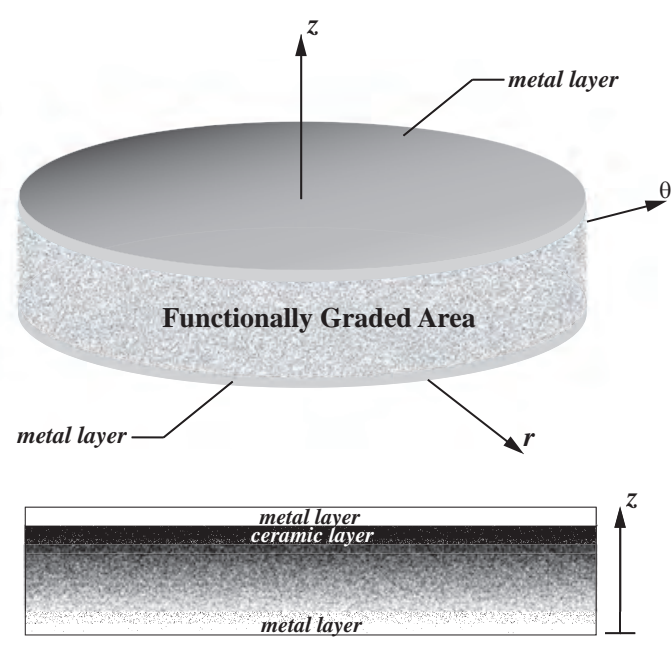

(a)

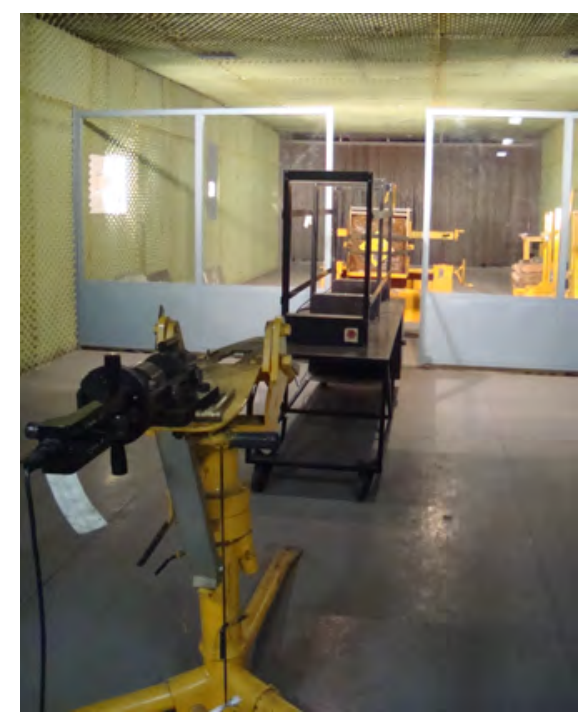

(b)

Figure 1: (a) Functionally graded sandwich plate and (b) Ballistic test system

in order to relieve thermo-mechanical mismatches along the bi-material interfaces; therefore, thermal residual stresses in such structures become more uniform in high temperature environments. Functionally graded materials have been increasingly used in the design of impact resistant structures as well as in the design of advanced thermal barrier coatings $[3,4]$. A functionally graded plate with a tailored ceramic to metal through-thickness gradient combines the superior features of ceramics and metals in the same material system. The ceramic side provides good protection against projectiles, while the metal-rich side offers toughness and strength to maintain the integrity of the structure as long as possible. Thus, the ceramic plates are used for single impact applications, whereas the FGM can be used multiple impact applications with high ballistic performance.

In this study, the damage and deformation mechanisms of aluminum and functionally graded sandwich plates have been investigated experimentally and their performances were compared to each other under ballistics impact loadings. Ballistic tests of aluminum and functionally graded sandwich materials manufactured with powder stacking-hot pressing method were performed with $9 \mathrm{~mm}$ x 19 Parabellum projectiles using a powder gun test system.

\section{Experimental procedure}

A functionally graded sandwich plate embodies two top and bottom metal surfaces between of which contains graded ceramic-metal compound layers where each layer is ordered according to their ceramic content ratio from bottom to top (Fig. 1a). Volume fraction of ceramic and metal is related with

$$
V_{c}+V_{m}=1
$$

The mixing rat6io of metal phase along with plate thickness $(h)$ is stated by

$$
V_{m}(z)=\left(1-\frac{z}{h}\right)^{n}
$$

where $V_{c}(z)$ is volumetric ratio of ceramic at any point along z-direction, $h$ is plate thickness, and $n$ is an arbitrary exponent controlling gradient of compound linearly or non-linearly.

\subsection{Sample fabrication method}

In general, functionally graded materials are manufactured via initially obtaining a functionally graded body with powder metallurgy methods and later sintering it [5]. The functionally graded sandwich and aluminum plates used in this study are manufactured with powder stacking-hot pressing method. For each layer of the sandwich, required ceramic and metal amounts are calculated by the mixture theorem for a linear composition. Volumetric 


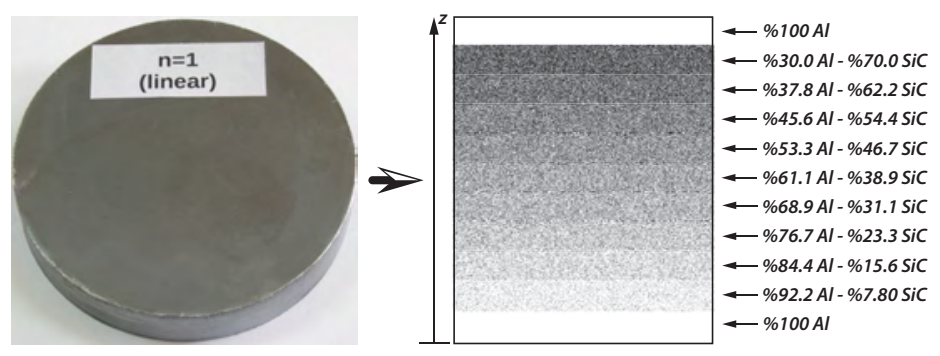

(a)

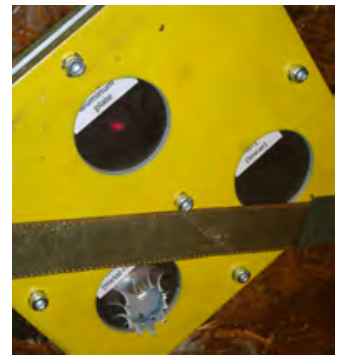

(b)

Figure 2: (a) Volume fraction ratio of functionally graded sandwich plate throughout the plate thickness and (b) Circular plates fixing method

ratios of layers for the FGM plate and their change along with plate thickness are given in Figure 2a. In FGM plates with $90 \mathrm{~mm}$ diameter and $16 \mathrm{~mm}$ thickness, 10 micron aluminum 6061 powder and an average of 50 micron silicon carbide powder were used as metal and ceramic components, respectively. For each layer, $\mathrm{Al}$ and $\mathrm{SiC}$ compounds are homogeneously mixed 5 hours in distinct containers before powder stacking and sintering process. Mixtured powder was laminated in sintering die, sintered under sufficient pressure at $600^{\circ}$ for 90 minutes, then cooled in the die under controlled pressure.

\subsection{Ballistic test actions}

Circular plates fixed to a putty block, Figure $2 \mathrm{~b}$, ballistic tests are conducted with powder gun test system (Fig. 1b) from $5 \mathrm{~m}$ distance by using $9 \mathrm{~mm}$ x 19 Parabellum projectile, and a $360 \mathrm{~m} / \mathrm{s}$ projectile velocity is measured with optic sensors. Aluminum surface at ceramic-rich side of plate is designated initial impact surface since considerable amount of projectile energy will dissipate during cracking hard ceramic-rich layer and thus projectile looses its impact due to barreling. Remaining energy will be dissipated by metal-rich rear layers.

\section{Results and discussion}

No perforation observed after both ballistic tests. While the projectile could completely penetrate into aluminum plate, it was only able to reach but not penetrate ceramic-rich layer (70\% SiC, 30\% Al) of FGM plate (Fig. 3). From figures, we can see a bloating at the back side of both aluminum and FGM plates, latter of which is notably smaller. Besides, cracks are observed at the back of aluminum plate due to fact that shock waves create compression stress at the front surface while creating tensile stress at the back surface resulting in cracks only if tensile stress is larger then yield stress.

In order to observe structures between layers after the tests, epoxy applied to plates, then they were cut from impact surface and polished. In Figure 4, projectile could penetrate into half of the aluminum plate and radial cracks are formed at the back. In Figure 5, it can be seen that projectile could penetrate only into initial aluminum

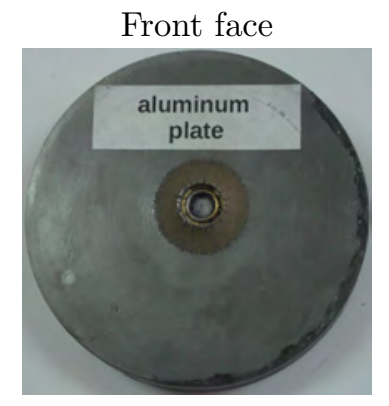

Aluminum plate
Rear face

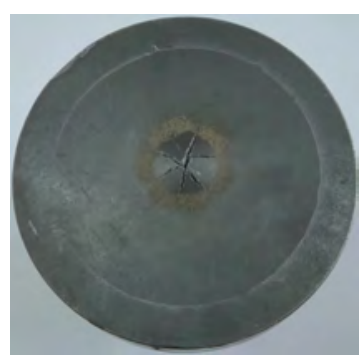

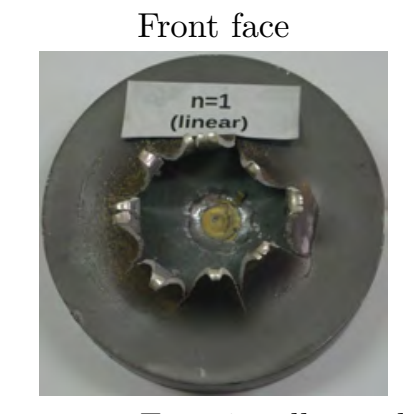

Functionally graded sandwich plate

Figure 3: Resultant deformation images after 9 mm x 19 Parabellum projectile hitting plates. 


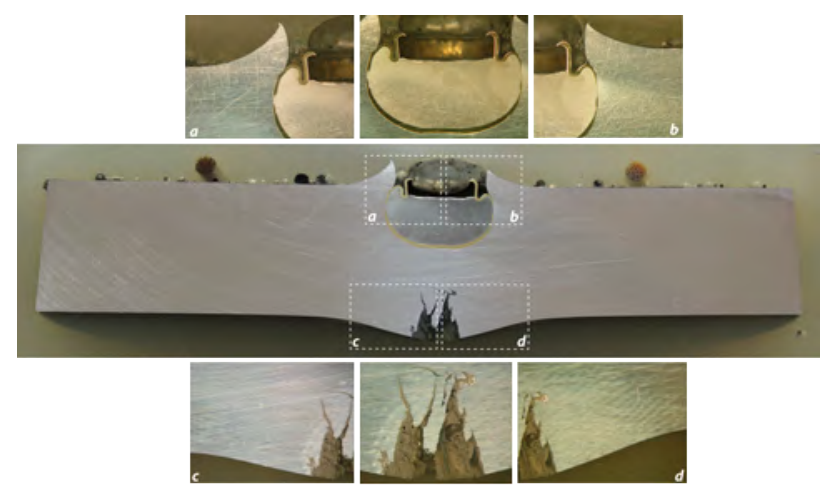

Figure 4: Section images after $9 \mathrm{~mm} \times 19$ Parabellum projectile hitting the aluminum plate.

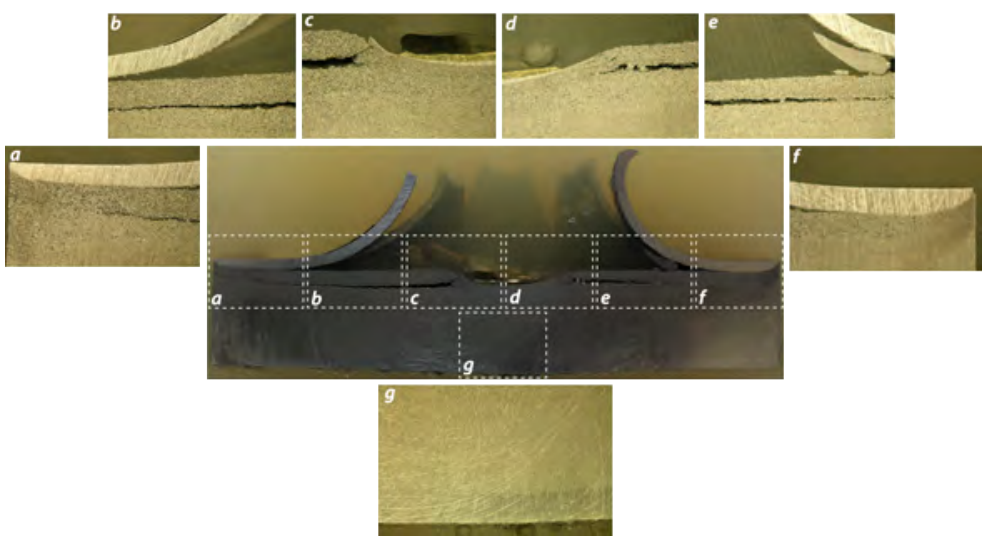

Figure 5: Section images after $9 \mathrm{~mm} \times 19$ Parabellum projectile hitting the functionally graded sandwich plate.

layer and due to shock waves it was peeled. On the other hand, delamination observed between $70 \% \mathrm{SiC}-30 \% \mathrm{Al}$ layer and the subsequent layer $(\mathrm{a}, \mathrm{b}, \mathrm{c}, \mathrm{d}, \mathrm{e}, \mathrm{f})$. It is also noted that no cracks observed at the back surface of the plate (g).

\section{Conclusions}

Comparing to aluminum plate, response of FGM plate to ballistic impact load and deformation mechanism is different. From this point, designing a functional structure and detecting optimum thickness is two key factors that will enable FGM plates to be used for ballistic purposes.

\section{Acknowledgements}

The authors would like to acknowledge funding from the Scientific and Technological Research Council of Turkey (TUBITAK) under the research Grant No. 112M917.

\section{References}

1. M. Yong, L. Iannucci, B.G. Falzon Efficient modelling and optimisation of hybrid multilayered plates subject to ballistic impact. International Journal of Impact Engineering, 37(6):605-624, 2010.

2. A. Seyed Yaghoubig, B. Liaw. Thickness influence on ballistic impact behaviors of GLARE 5 fiber-metal laminated beams: Experimental and numerical studies. Composite Structures, 94(8):2585-2598, 2012.

3. Ernest S.C. Chin. Army focused research team on functionally graded armor composites. Materials Science and Engineering: A, 259(2):155-161, 1999.

4. M. Ubeyli, E. Balci, B Sarikan, M. K. Oztas, N. Camuscu, R. O. Yildirim, O. Keles. The ballistic performance of SiCAA7075 functionally graded composite produced by powder metallurgy. Materials and Design, 56:31-36, 2014.

5. B. Kieback, A. Neubrand, H. Riedelc. Processing techniques for functionally graded materials. Materials Science and Engineering: A, 362(1-2):81-105, 2003. 